\title{
Review
}

\section{A Review of Psychopathology Features, Personality, and Coping in Myotonic Dystrophy Type 1}

\author{
Lisa Minier $^{\mathrm{a}, *}$, Baptiste Lignier ${ }^{\mathrm{b}, \mathrm{c}}$, Cyrille Bouvet $^{\mathrm{a}}$, Benjamin Gallais ${ }^{\mathrm{d}, \mathrm{e}}$ and Nathalie Camart ${ }^{\mathrm{a}}$ \\ ${ }^{a}$ Department of Psychology, Laboratoire CliPsyD, EA4430, Université Paris Nanterre, France \\ ${ }^{\mathrm{b}}$ Department of Psychology, Laboratoire Psy-DREPI, EA 7458, Université de Bourgogne \\ Franche-Comté, Dijon, France \\ ${ }^{\mathrm{c}}$ Espace Psychothérapique, pôle B Côte-d'Or Sud de Psychiatrie Générale, CH La Chartreuse, \\ Dijon, France \\ d ÉCOBES - Recherche et transfert, Cégep de Jonquière, QC, Canada \\ ${ }^{\mathrm{e}}$ Groupe de Recherche Interdisciplinaire sur les Maladies Neuromusculaires (GRIMN), Jonquière, \\ $Q C$, Canada
}

\begin{abstract}
.
Background: The last literature review on psychopathological features in Myotonic Dystrophy type 1 had been conducted by Ambrosini and Nurnberg in 1979. Since that date, many researches had been carried out.

Objective: The aim of this study is (i) to systematically obtain and evaluate the relevant literature on psychopathological features, personality, and coping in individuals with adult phenotypes of Myotonic Dystrophy type 1. (ii) To summarize current research findings and draw conclusions for future research.

Methods: A systematic search was conducted on Pubmed, PubPsych, PsycInfo, Science Direct, and Scopus covering the period of January 1979 to July 2017.

Results: In view of our literature review, patients show mild psychopathological problems, such as interpersonal difficulties, lack of interest, dysphoria, concern about bodily functioning, and hypersensibility. However, they do not experience more psychiatric disorder in comparison to the general population, except for personality disorders and depression. We discussed problems concerning depression's assessment tool. Patients also present symptoms of several personality disorders: avoidant personality disorder was the most common. Finally, coping strategies relative to limitations resulting from their disease have a negative impact on their quality of life.

Conclusions: In conclusion, Myotonic Dystrophy type 1 patients did not present homogeneous psychopathological and psychological features. However, based on tendencies observed among Myotonic Dystrophy type 1 patients, elements to conceptualize their social difficulties are provided.
\end{abstract}

Keywords: Myotonic dystrophy 1, psychopathology, depression, personality, emotion

\footnotetext{
${ }^{*}$ Correspondence to: Lisa Minier, Doctorante en psychologie clinique (PhD student) Laboratoire CliPsyD, EA4430, Université Paris Nanterre, 200, avenue de la République 92000 Nanterre, France. E-mails: minier.lisa@gmail.com and minierl@ parisnanterre.com.
}

\section{INTRODUCTION}

Myotonic Dystrophy type 1 (DM1), also known as Steinert disease, is the most common form of adult muscular dystrophy (prevalence of 10 for 
100 000) [1]. This progressive multisystem disease, associated with an abnormal expansion of a CTG repeat on chromosome 19 , is inherited and worsens from generation to generation. Maternal inheritance and age of first symptoms are aggravating factors. The principal features are myotonia (difficult and slow relaxation after voluntary muscle contraction), myopathy (muscle weakness), and muscular atrophy. Ocular (mainly cataracts), cardiac and gastrointestinal (such as oropharyngeal dysphagia, which leads to chocking) impairments, cognitive impairment (such as dysexecutive syndrome, emotional blunting, and apathy), and excessive fatigue might be associated [2]. Symptoms vary from one patient to another. There is no pharmaceutic treatment.

A previous review of DM1 patients' psychopathological characteristics had been made in 1979 [3]. Memory disturbance, inattentiveness, apathy, hypersomnia, and intellectual degradation were typical manifestations of the disease. Patients also showed some "characterial" manifestations such as indolence, moodiness, rumination, and reduced ethical sense. Some cases of schizophrenia are mentioned. Furthermore, one study [4] reported schizoid (defined as a lack of interest in things and being seclusive), paranoid (defined as having paranoid beliefs), epileptoid (defined as having atypical fits and sudden paralysis), hypomanic (defined as being persistently mildly elated and atypical behaviors, such as promising to give doctors "guineas for some small errand") and hysteroid (defined as having hallucinations and delusional thoughts, such as having "supernatural powers") manifestations. Authors empathized the fact that altered mental functioning is a basic feature of Myotonic Dystrophy, due to the central nervous system impairment, rather than a reactive phenomenon.

Since 1979 research on psychological (in particular on personality and coping strategies) and psychopathological features in DM1 has been conducted. Therefore, the aim of this review is to investigate psychopathology (ie- psychiatric symptoms and/or disorders according to DSM criteria), personality, and coping in individuals with adult phenotypes of DM1, by reviewing articles published since 1979 on these topics. Are DM1 patients depressed? Is there any psychopathological, personality and coping profile in adult phenotypes of DM1? Are Ambrosini and Nurnberg's [3] findings confirmed?

\section{METHODS}

A systematic search on Pubmed, PubPsych, PsycInfo, Science Direct, and Scopus was conducted from May to July 2017 covering the period of January 1979 to July 2017, using the association of "Steinert disease" or "Myotonic Dystrophy" or "DM1" with one of the following key-words, using the connector "AND": "psychiatric characteristics", "psychological characteristics", "psychopathology", "depression", "anxiety" "personality", “coping”, and "emotion". One author (LM) had read titles and abstracts and selected potentially relevant papers. Then, two authors (LM and BL) had independently read full texts and applied inclusion criteria. Results and uncertainties were discussed by the authors.

Inclusion criteria were the following: (i) scientific articles (book chapters, thesis, correspondence, transcriptions and abstracts of oral communications were excluded), (ii) written in English or French, (iii) published from 1979 (date of the last literature review on adult DM1 psychopathology features) [3], (iv) recruited patients with adult phenotypes of DM1 (v) assessed psychopathology and/or psychological features (such as personality or emotional processes), (vi) used scientific design and tools (ie- standardized measures).

\section{RESULTS}

Of the 309 initial articles, 44 articles matched our inclusion criteria and were kept in this systematic review. Of the 265 excluded articles, 10 articles were not scientific articles, 10 articles were written in another language, 11 articles did not use standardized measures, 32 articles concerned other phenotypes of Myotonic Dystrophy (DM2, congenital, infantile and juvenile DM1), 129 articles addressed other impairment (medical, cognitive, fatigue, douleur, and quality of life), 2 articles concerned patients' relatives, 3 were animal studies, and 68 articles were not studies on Myotonic Dystrophy. Of the 44 included articles, 27 studies assessed psychiatric symptoms and disorders, and among them 22 articles focused on depression and anxiety (we presented depression/anxiety independently of general psychopathology since it was independently studied in literature), 13 assessed personality (personality disorders and normal personality traits), and 4 assessed coping. Figure 1 summarizes the selection process. 


\section{DEPRESSION AND ANXIETY}

In the DM1 population, the prevalence, at the time of the studies, of Major Depressive Disorder varied from $2.50 \%$ to $23.70 \%$ [5-9]. In comparison, in the general population, lifetime prevalence of Major Depressive Disorder ranged from 1\% (Czech Republic) to $16.90 \%$ (United States), the 12-month prevalence estimates ranged from $0.30 \%$ (Czech
Republic) to $10 \%$ (United States) [10]. In some studies, DM1 patients presented mild depressive symptomatology or depressiveness (prevalence, at the time of the studies, ranged from $12.50 \%$ to $50 \%$ ) [9, 11-15], moderate depressive symptomatology (prevalence, at the time of the studies, ranged from $11.10 \%$ to $51 \%$ ) [16-20], or no depression at all [21, 22]. Winblad et al. [13] compared DM1 patients with white matter lesions to ones without lesions: patients

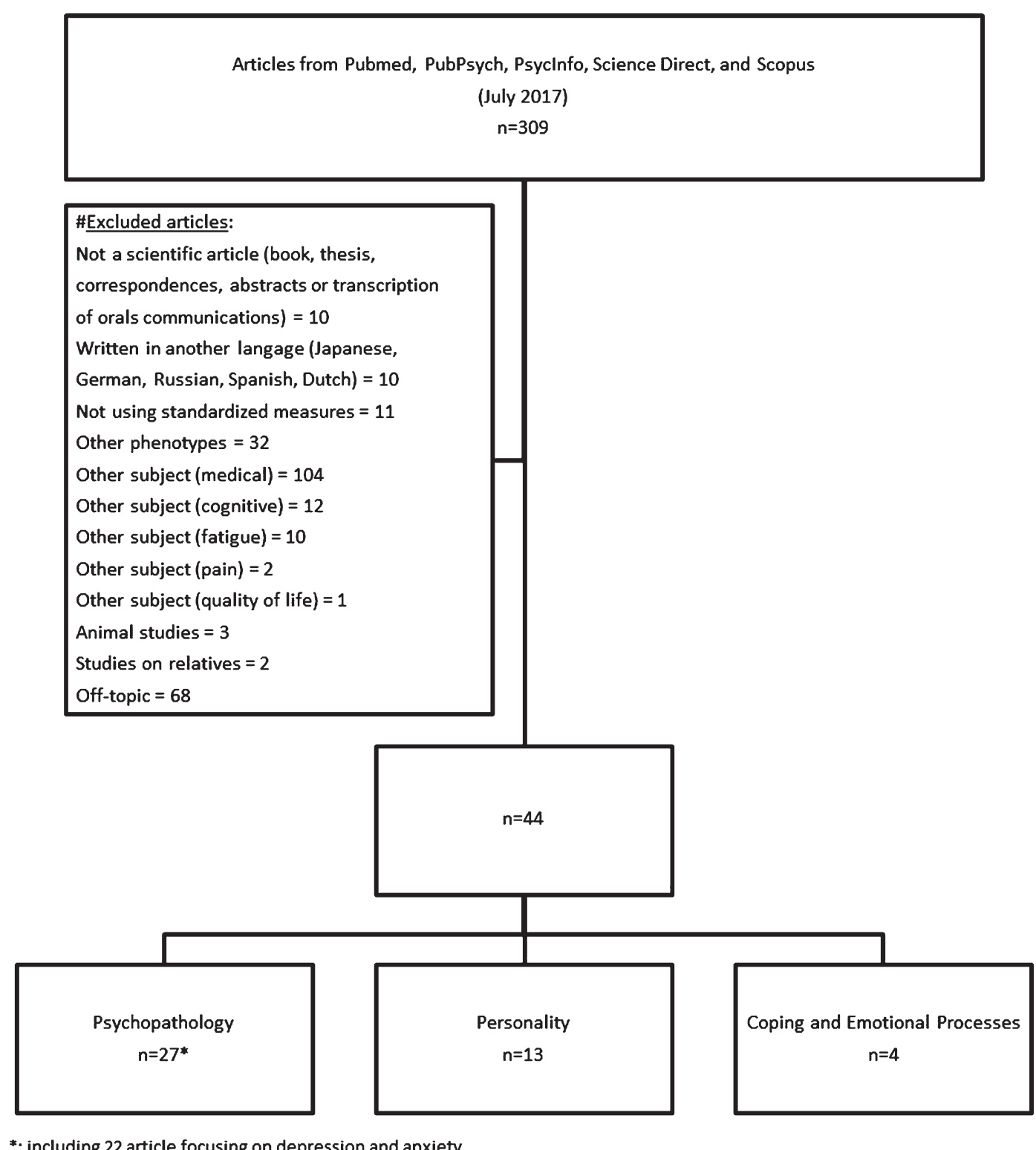

Fig. 1. Flow chart of literature search and selection 
showing brain damage had significantly lower scores of depression. In studies comparing DM1 patients with healthy control groups, DM1 patients presented higher scores of depression [5, 7-9, 23, 24]. Authors highlighted the fact that somatic and performances items of depression scales were scored higher for DM1 patients, than cognitive and affective items $[13,25]$. In their study, Rose et al. [26] included several muscle diseases (including myotonic dystrophy) and did not find any significant difference for both depression and anxiety rates. Duveneck et al. [24] only used the 2-D (Depression) scale of the MMPI (Minnesota Multiphasic Personality Inventory) [27] to assess depression. The MMPI, and now the MMPI-2 and MMPI-2-RF, is the most used psychopathological test to evaluate the severity of psychiatric diagnoses [28]. They found that the DM1 group was the most depressed group in comparison to paraplegic and healthy groups. DM1's depression rate was similar with the one found in the limb-girdle syndrome group. Brumback et al. [29] also used the MMPI to compare DM1 patients with other somatic diseases. They found that all groups had elevated 1-Hs (Hypochondriasis: "somatic concerns and importance of bodily functions" [30]) and 3-Hy (Hysteria: "optimistic and cheerful in the face of difficulties, using denial and rationalization" [30]) scales. DM1 patients had higher scores on the 2-D (Depression) scale and showed high prevalence of affective symptoms (from DSM-III major depressive disorder criteria) [31]. Prevalence data are detailed in Table 1. Palmer et al. [22], using the Millon Clinical Multiaxial Inventory (MCMI-II) [32], also found that $31 \%$ of their DM1 sample showed dysthymia. Both Gallais et al. [5] and Rubinsztein et al. [6] found that apathy and hypersomnia levels were not correlated with depression in their studies. Furthermore, Gallais et al. [5] found higher apathy rates than depression rates (39.5\% and $23.7 \%$ respectively) in their DM1 sample. These results highlight the idea that apathy and hypersomnia might be independent of depression, but may be confounded with depression, because of the proximity of some of their manifestations. In addition, both Gallais et al. [5] and Winblad et al. [13] assume that the patients' lack of facial expression, due to muscle weakness, may be confused with depressive symptom.

Although most studies comparing depression and anxiety in the DM1 population found higher scores of depression, some studies found similar scores [20] or even higher scores of anxiety [18, 19]. All studies considered, anxiety rates vary from $0 \%$ to $54.8 \%$
[7, 9, 11, 15, 17-20, 22, 33]. Both depression and anxiety had an influence on DM1 patients' quality of life $[9,11,34]$. Mood appears to be strongly associated with quality of life in muscle disease in general, as reflected in Graham et al. [35]'s literature review's conclusions.

To summarize, DM1 patients seem to present higher rates of depression than the healthy general population, but also than those with other somatic diseases. Apathy and hypersomnia, which are symptoms inherent of DM1, seem to contribute to higher depression rates, because of potential assessing biases. Furthermore, patients presenting depression and anxiety are more likely to have poor quality of life. Main results on depression and anxiety are provided in Table 1.

\section{STUDIES ASSESSING PSYCHIATRIC SYMPTOMS AND DISORDERS OTHER THAN DEPRESSION AND ANXIETY}

Latest review of literature [3] reported prevalence for schizophrenia that varied from $0 \%$ to $30 \%$. One study [4] reported schizoid, paranoid, epileptoid, hypomanic, and hysteroid manifestations. The prevalence of these manifestations was $20.69 \%$ (two cases presenting hypomanic manifestations and one case for each other).

More recently, Kalkman et al. [36], have investigated the prevalence of psychiatric disorders in Dutch DM1 patients. In their sample, 33\% of DM1 patients presented a psychiatric disorder in their lifetime and $11 \%$ presented one at the time of the study (depression or agoraphobia). Authors did not find any correlations between psychiatric disorders and fatigue or muscular impairment. The prevalence of psychiatric disorder found in this study is similar to the Dutch general population's prevalence (41\% reported having presented at least one psychiatric disorder in their lifetime, and 19\% of them had experienced a mood disorder). In Palmer et al.'s [22] study, $38 \%$ of DM1 patients presented somatization. Bird et al. [30] used the MMPI to assess DM1 patients' psychopathology. They found that $64 \%$ patients had at least one elevated scale and $40 \%$ had three or more elevated scales. Patients with maternal inheritance, and ones with higher physical handicap, tended to have more elevated scales than the others. By combining clinical interview and results of the MMPI, authors found that $44 \%$ patients had no personality impairment, $24 \%$ showed mild personality difficulties (did not impact their 
Table 1

Main results on depression

\begin{tabular}{|c|c|}
\hline First author Year & Methodology (n) \\
\hline Gallais B [5] 2015 & $\begin{array}{l}\text { Apathy: LARS; } \\
\text { Depression: MADRS; } \\
\text { Psychopathology: MINI } \\
\text { DM1 (38), FSHD (19), Healthy (20) }\end{array}$ \\
\hline Peric Sa [16] 2014 & $\frac{\text { Depression: HamD }}{\text { DM1 (66) }}$ \\
\hline Peric Sb [33] 2014 & $\frac{\text { Psychopathology: MCMI-II }}{\text { DM1 (66) }}$ \\
\hline Rakocevic- Stojanovic & Depression and anxiety: HamD and HamA; \\
\hline V [11] 2014 & $\begin{array}{l}\text { Fatigue: DSS; FSS; } \\
\text { Quality of life: INQoL } \\
\text { DM1 (44) }\end{array}$ \\
\hline Peric S [34] 2013 & $\begin{array}{l}\text { Depression: Ham-D } \\
\text { Quality of life: SF-36 } \\
\text { Acceptance of illness: AIS } \\
\text { DM1 (120) }\end{array}$ \\
\hline $\begin{array}{l}\text { Kobayakawa M [23] } \\
2012\end{array}$ & $\begin{array}{l}\text { Depression: SDS } \\
\text { DM1 (9), Healthy (12) }\end{array}$ \\
\hline Rose MR [26] 2012 & $\begin{array}{l}\text { Depression and anxiety: HADS } \\
\text { Quality of life: SF-36, INQoL } \\
\text { Muscle disease (302 including } 79 \text { DM) }\end{array}$ \\
\hline
\end{tabular}

Graham CD [35] 2011 Review of literature

Main results

Apathy: DM1 : 39.50\%; FSHD: 21.10\%; Healthy: 0\%

Major Depression Episode: DM1 : 23.70\%;

FSHD: $5.30 \%$; Healthy: 0\%

Depression scores higher than 17:16\%

One psychopathological scale elevated $(n=41): 66.10 \%$

Anxiety scale (most common): $54.80 \%$

Depressiveness: 20\%; Anxiety: 16\%

Quality of life associated with fatigue, mood impairments, excessive daytime sleepiness

Both physical and mental quality of life domains are impaired

Poorer quality of life: depressed, elder patients, with poor acceptance of illness

DM1 patients: no fatigue nor apathy symptoms

Depression scores higher in DM1 group

Depression and anxiety: no significant difference between the groups

All the SF-36 domains are negatively impacted

Depression impacted "Fatigue", "Social" and "Emotional domains of the INQoL

Mood: strongly correlated with quality of life

Fatigue and sleep: correlated with poor quality of life and physical functioning

Pain: correlated with psychosocial and physical domains of quality of life

\begin{tabular}{|c|c|}
\hline Boyer FC [18] 2011 & $\frac{\text { Depression and anxiety: HADS }}{\text { DM1 (35) }}$ \\
\hline Minnerop M [12] & Depression: BDI \\
\hline 2011 & $\overline{\mathrm{DM}} 1$ (22) \\
\hline Kierkegaard M [21] & Depression and anxiety: HADS; \\
\hline 2011 & $\begin{array}{l}\text { Fatigue: ESS; FSS } \\
\text { DM1 (70) }\end{array}$ \\
\hline
\end{tabular}

Peric S [17] 2010 Depression and anxiety: HamD and HamA Quality of life: SF-36

DM1 (79), SLA(74)

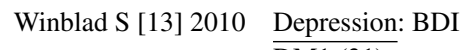
$\overline{\mathrm{DM} 1(31)}$

Timman R [14] 2010 Depression and anxiety: HADS DM1 (69), Partners (69)

Pais-Ribeiro J [19] Depression and anxiety: HADS 2007 DM1 (18)

Antonini G [15] 2006 Depression and anxiety: HamD and HamA; STAI;

Quality of life: SF-36 DM1 (20), Healthy (20)

Phillips MF [25] 1999 Depression and anxiety: BDI; HADS DM1 (35), CMT (13), Healthy (16)

Rubinsztein JS [6] Psychopathology: SADS-L; 1998 Apathy: AES; Fatigue: Fatigue questionnaire DM1 (36)

Bungener C [7] 1998 Depression and anxiety: SCID; MADRS; HAM-D, Covi and Tyrer anxiety scales; Emotional blunting: AT;
Anxiety: $17.10 \%(n=6)$;

Depression: $11.40 \%(n=4)$

Mild depression: $32 \%$

No clinical depression

No association between severity of muscular impairment, daytime sleepiness, fatigue, depression, and anxiety

Moderate depression: DM1 : 51\%; SLA: 3\%

Anxiety: DM1 : $38 \%$; SLA: $4 \%$

Quality of life: similar results expect for bodily pain (DM1 higher than SLA)

Mild depression: $32 \%$

Moderate depression: DM1 : 14\%; Partners: $16 \%$

Anxiety: $16.70 \%$;

Moderate depression: $11.10 \%$

DM1: Mild depression: 50\%; Anxiety: 40\%

Health related quality of life: DM1 lower than Healthy

DM1's quality of life was correlated with physical disability and changes in respiratory functions

Depression: DM1 higher than CMT \& Healthy

Anxiety: no significant difference

Major Depression Episode: 5.60\%

High apathy levels cannot be explained by clinical depression.

No correlation between apathy and hypersomnolence

Major Depression Episode: DM1 : 6.70\%; FSHD: 0\%; Healthy: 0\%

Anxiety: none 
Table 1

(Continued)

\begin{tabular}{|c|c|c|}
\hline First author Year & Methodology (n) & Main results \\
\hline & $\begin{array}{l}\text { Anhedonia: PAS and SAS } \\
\text { DM1 (15), FSHD (14), Healthy (14) }\end{array}$ & $\begin{array}{l}\text { Emotional blunting and anhedonia: DM1 higher than FSHD }(n=11) \\
\& \text { Healthy }\end{array}$ \\
\hline Bungener C [8] 1996 & $\begin{array}{l}\text { Depression and anxiety: DSM III R (Mood } \\
\text { Disorders); MADRS; HDRS; Covi and } \\
\text { Tyrer anxiety scales; Jouvent depression } \\
\text { scale; } \\
\text { Emotional blunting: AT } \\
\text { DM1 (15), FSHD (12), Healthy (14) }\end{array}$ & $\begin{array}{l}\text { Major Depressive Episode: DM1 : } 6.70 \%(n=1) \text {; FSHD: } 16.70 \% \\
(n=2) ; \text { Healthy: } 0 \%\end{array}$ \\
\hline Palmer BW [22] 1994 & $\frac{\text { Psychopathology: MCMI-II }}{\text { DM1 (21) }}$ & Anxiety: $46 \%$; Dysthymia: $31 \%$ \\
\hline Colombo G [9] 1992 & $\frac{\text { Depression and anxiety: SADS; SRT }}{\text { DM1 (40), Healthy (20) }}$ & $\begin{array}{l}\text { DM1 : } 65 \% \text { reduced interest in vocational activities } \\
\text { Depressive disorder: DM1 : } 17.50 \% \text { (1 Major, } 5 \text { Minor, } 1 \text { Chronic); } \\
\text { Healthy: } 10 \% \text { (2 Minor) } \\
\text { Anxiety disorder: DM1 } 10 \% \text { (3 Panic, } 1 \text { Generalized); Healthy: } 0 \%\end{array}$ \\
\hline Cuthill J [20] 1988 & $\begin{array}{l}\text { Depression and anxiety: HamD and HamA; } \\
\text { SDS } \\
\text { DM1 (13) }\end{array}$ & $\begin{array}{l}\text { Moderate depressive symptomatology: } 15.40 \%(n=2) \\
\text { Anxiety: } 15.40 \%(n=2)\end{array}$ \\
\hline $\begin{array}{l}\text { Brumback RA [29] } \\
1987\end{array}$ & $\begin{array}{l}\text { Depression: criteria for DSM-III Major } \\
\text { Depressive Disorder } \\
\text { Personality: MMPI } \\
\text { DM1(16) }\end{array}$ & $\begin{array}{l}\text { Dysphoria: } 93.75 \% \text {; Sleep Disturbance: (i) Terminal Insomnia: } \\
\text { 100\%, (ii) Hypersomnia: } 25 \% \text {; Fatigue/low energy: } 81.25 \% \text {; Lack } \\
\text { of interest or pleasure: } 75 \% \text {; Appetite disturbance: } 62.50 \% \text {; Slowed } \\
\text { thinking: 50\%; Diurnal mood variation, Psychomotor retardation: } \\
\text { 43.75\%; Other symptoms were found in less than } 40 \% \text { Depression: } \\
50 \%\end{array}$ \\
\hline $\begin{array}{l}\text { Duveneck MJ [24] } \\
\quad 1986\end{array}$ & $\begin{array}{l}\text { Personality: MMPI(Depression and Ego } \\
\text { Strength scales); IPAT (Depression, } \\
\text { Suicide Probability and Hopelessness } \\
\text { scales) } \\
\text { DM1 (27), LSG (11), Paraplegic (17), } \\
\text { Healthy (27) }\end{array}$ & Depression: DM1 \& LSG higher than Paraplegic \& Healthy \\
\hline
\end{tabular}

Note: For more clarity, we did not develop all results. AES = Apathy Evaluation Scale; AIS = Acceptance of Illness Scale; AT = Abrams and Taylor scale for emotional blunting; BDI=Beck Depression Inventory; CL = Cantril's Ladder; CMT =Charcot-Marie-Tooth; DM = Myotonic Dystrophy; DM1 = Myotonic Dystrophy type 1; DSS = Daytime Sleepiness Scale; ESS=Epworth Sleepiness Scale; FSHD = Facioscapulohumeral Dystrophy $;$ FSS = Fatigue Severity Scale $;$ HADS = Hospital Anxiety and Depression Scale; HamA = Hamilton scale for anxiety; HamD = Hamilton scale for depression; HDRS = Hamilton Depression Rating Scale; HRQoL = Health-Related Quality of Life; INQoL = Individualized Neuromuscular Quality of Life Questionnaire; IPAT = Institute for Personality and Ability Testing; KT = Kaasas Test; LARS = Lille Apathy Rating Scale; LSG=Limb-girdle Syndrome; MADRS = Montgomery and Asberg Depression Rating Scale; MCMI-II = Millon Clinical Multiaxial Inventory; MINI = Mini International Neuropsychiatry Interview; MMPI = Minnesota Multiphasic Personality Inventory; $\mathrm{OQoL}=$ Overall Quality of Life; PAS and SAS = Questionnaires for physical and social anhedonia; SADS-L = Schedule for affective disorder and schizophrenia-Lifetime version; SCID = DSM III-R semi-structured interview; SDS: Zung Self-Rating Depression Scale; SF-36 = 36-item Short Form Health Survey; SLA = Amyotrophic Lateral Sclerosis; SRT = Symptom Rating Test; STAI = State-Trait Anxiety Inventory; WB = Well-being.

social functioning), and $32 \%$ showed predominant personality abnormalities (impacting their interaction with others). The most elevated scales were 8-Sc (Schizophrenia), 1-Hs (Hypochondriasis) and 3-D (Depression). The MMPI profiles configuration corresponds to schizoid personality or symptoms close to schizophrenia. Some patients also had elevated 3-Hy (Hysteria), 4-Pd (Psychopathic deviate) and F (Frequency scale). In 1991, Franzese et al. [37] found that $45.80 \%$ patients had elevated 1-Hs (Hypochondriasis) scale, $16.60 \%$ patients had elevated 8 -Sc (Schizophrenia) scale and $10.70 \%$ patients had elevated 4-Pd (Psychopathic deviation) scale. Authors concluded that although patients did not show real psychiatric diagnosis, they showed some psychological distress such as sadness, dysphoria, anxiety and tension, and hypersensibility towards others. More recently, Serra et al. [38] used the MMPI-2 and found $10 \%$ of patients without elevated scales, $89 \%$ with at least one elevated scale. They also found that $37 \%$ of patients had mild psychiatric abnormalities and 53\% had greater impairments. The most elevated scales were 8-Sc (Schizophrenia), 6-Pa (Paranoid) and 1-Hs (Hypochondriasis).

To summarize, DM1 patients did not seem to experience greater psychiatric disorder than that of the general population. Although DM1 patients did not fulfill psychiatric diagnosis, authors mentioned 
mild psychopathological problems; such as interpersonal difficulties, lack of interest, dysphoria, concern about bodily functioning, hypersensibility, etc. These symptoms may be at play in the social difficulties show by a third of the patients. Main results on general psychopathology are provided in Table 2 .

\section{PERSONALITY DISORDERS AND PERSONALITY TRAITS}

Personality disorders are defined as a pattern of typical and problematic behaviors that is remarkably different from cultural norms and appears distinctly in cognition, emotion, relationships and self-control [39]. The categorical approach has been used to assess personality of DM1 patients. Bungener et al. [8] and Delaporte [40] used DSM-III's criteria of personality disorders [31]. They found that $26.57 \%$ of DM1 patients fulfilled criteria for avoidant personality disorder. They also found many obsessive-compulsive, schizotypal, paranoid, and passive-aggressive personality traits. Although patients showed personality disorder criteria, they did not fulfill the whole personality disorder diagnosis. Authors' conclusion was that DM1 patients showed an anxious personality pattern and an important social avoidance, since this is a common trait in all these personality disorders, with the exception of obsessive-compulsive personality. DM1 patients seemed to have high rigidity and stubbornness in thoughts and attitudes with problems in their relationships and difficulties to communicate with others. Moreover, no link was found with the CTG repetition. Palmer et al. [22] also found that DM1 patients showed signs of dependency and submissiveness. Meola et al. [41] conducted a similar study using the Structured Clinical Interview for Disorders (SCID) I and II [42, 43]. None of the patients fulfilled DSM-IV [44] criteria but results showed significant avoidant behavioral traits. Sistiaga et al. [45] used the MCMI-II and found that DM1 patients showed narcissistic, antisocial, aggressive/sadistic, paranoid, psychotic thought, sincerity traits but only aggressive/sadistic and paranoid traits are significantly higher in DM1 than controls. Peric et al. [33] also used the MCMI-II and found that almost $60 \%$ of their sample presented personality impairment. The most frequent personality traits were dependent and paranoid. They remind that personality disorders in the general population were only $6 \%$ [46]. Personality can also be conceptualized with a dimensional approach with a set of dimensions, or personality traits, present in everyone. For instance, the CPI (California Psychological Inventory) [47] provides scores on personality traits rather than personality disorders. Fowler et al. [48] showed that DM1 patients had lower scores on sociability, sense of well-being, socialization, self-control, tolerance, good impression, achievement, intellectual efficiency, psychological mindedness, and flexibility. Cloninger et al. [49] conceptualized a biosocial

Table 2

Main results on general psychopathology

\begin{tabular}{|c|c|c|}
\hline First author Year & Methodology (n) & Main results \\
\hline \multirow[t]{2}{*}{ Serra L [38] 2014} & Personality: MMPI-2 & Mild psychiatric problems: $37 \%$ \\
\hline & $\overline{\mathrm{DM}} 1(27)$ & Greater psychiatric problems: $53 \%$ \\
\hline \multirow[t]{2}{*}{ Kalkman JS [36] 2007} & Psychopathology: SCL-90 & At least one lifetime psychiatric disorder: $33 \%$ \\
\hline & DM1 (70) & Current psychiatric disorder (1-month): $11 \%$ \\
\hline \multirow[t]{2}{*}{ Palmer BW [22] 1994} & Psychopathology: MCMI-II & Somatization: $38 \%$ \\
\hline & $\overline{\text { DM1 (21) }}$ & Paranoia signs: $4.76 \%(n=1)$ \\
\hline \multirow[t]{4}{*}{ Franzese A [37] 1991} & Personality: MMPI & In general: normal MMPI profile \\
\hline & DM1 (24) & 1-Hs elevated: $45.80 \%(n=8)$ \\
\hline & & 8-SC elevated: $16.60 \%(n=5)$ \\
\hline & & 4-Pd elevated: $10.70 \%(n=4)$ \\
\hline Brumback RA [29] 1987 & $\frac{\text { Personality: MMPI }}{\text { DM1 (16) }}$ & 8-SC, 1 -Hs, and 3-Hy elevated \\
\hline Bird TD [30] 1983 & $\frac{\text { Personality: MMPI }}{\text { DM1 (29) }}$ & Mild psychiatric problems: $56 \%$ \\
\hline Ambrosini PJ [3] 1979 & $\underline{\text { Literature review }}$ & $\begin{array}{l}\text { In Maas et al. [4]: schizoid }(n=1) \text {, paranoid }(n=1) \text {, epileptoid }(n=1) \text {, } \\
\text { hypomanic }(n=2) \text {, hysteroid }(n=1) \text { manifestations }\end{array}$ \\
\hline
\end{tabular}

Note: For more clarity, we did not develop all results. 1-HS = Hypochondriasis MMPI scale; 4-Pd= Psychopathic deviation MMPI scale; 8-SC = Schizophrenia MMPI scale; BDI = Beck Depression Inventory; DM1 = Myotonic Dystrophy type 1; MCMI-II = Millon Clinical Multiaxial Inventory; MMPI = Minnesota Multiphasic Personality Inventory; SCID-I=Structured Clinical Interview for DSM-IV (axis I disorders); SCL-90 = Symptom Checklist-90. 
dimensional model of personality: the Biosocial Personality Model, and a tool to assess these dimensions: The Temperament and Character Inventory (TCI). Winblad, Lindberg and Hansen [50] used the TCI and found that DM1 patients showed higher scores on Harm Avoidance, lower scores on Persistence, Cooperativeness, and Self-directedness. These results confirmed the anxious and inhibited pattern found previously with personality disorders, the social inhibition, and the excessive fatigue of DM1 patients. Authors hypothesized that the patients' reduced facial expressivity combine with anxietyrelated behavioral inhibition may have contributed to a poor development of Self-directedness and Cooperation (which are the character dimensions). They summarized their results by describing DM1 patients as "introverted individual with low self-esteem, burdened by fatigue and low energy and social withdrawal". Winblad et al. [51] reused the TCI with facial emotion recognition tasks with DM1 patients. They found a correlation between facial emotion recognition ability and the sociability dimensions of the TCI, such as Cooperativeness and Dependence. Kobayakawa et al. [52] and Takeda et al. [53] found that DM1 patients had difficulties to recognize facial expressions of anger and disgust. These difficulties were associated with white matter lesions that could partly explain patients' interpersonal difficulties.

Clinical and social psychologists agreed that the most significant individual personality differences can be reduced into five broad traits or dimensions generally known as the Five Factors Model (or "Big Five"), which may be characterized as: E for Extraversion, Energy, Enthusiasm; A for Agreeableness, Affection, Altruism; C for Conscientiousness, Constraint, Control; $\mathrm{N}$ for Neuroticism, Negative emotionality, Nervousness, and $\mathrm{O}$ for Openness, Originality, Open-Mindedness [54]. Only two studies used this Five Factors Model to assess DM1 patients' personality, and they both used the NEO Five Factor Inventory (NEO- FFI) [55]. Laberge et al. [56] found that a low score on Conscientiousness contributed to poor mental health function (such as apathy) and that poorer physical health function is associated with lower scores on Neuroticism. Bertrand et al. [57] found that mean group Big Five scores are within the normal limits but that $27 \%$ of the patients showed higher scores on Neuroticism and lower scores on Agreeableness. Those patients presented a high risk of developing a psychiatric disorder. Scores are within normal limits but differences appear when patients are divided into groups.
Mild-DM1 group (a lighter form than the classical DM1 adult phenotype; with smaller CTG repeats and first symptoms onset after 40 years old) presented less paranoid ideation and psychoticism than Adult Onset group (classical DM1 adult phenotype). Adult Onset group had lower scores on Openness and Conscientiousness, and presented a higher risk of developing a psychiatric disorder.

To summarize, studies using personality disorders and dimensional tools show that DM1 patients exhibited traits of several personality disorders: avoidant, obsessive-compulsive, schizotypal, paranoid, passive-aggressive, narcissistic, and antisocial. Dimensional models show that a proportion of DM1 patients report higher scores on Harm Avoidance and lower scores on Persistence, Cooperativeness and Self-directedness. These dimensions and disorders show interpersonal difficulties and anxiety. These patients tend to avoid new situations and have difficulty to commit with others. It is possible that these results are related to DM1 experience or to the Central Nervous System (CNS)-related symptoms occurring in DM1, such as apathy and cognitive impairment. Main results on personality are provided in Table 3.

\section{COPING}

Coping is a process by which one handles a stressful situation. Coping is part of Lazarus and Folkman's transactional model of stress [58]. In this model, one can use two kinds of coping strategies. The first, called problem-focused, includes all strategies used by one to decrease his/her expectations and/or increase his/her resources to face the situation. The second kind of coping is called emotion-focused and regroups all strategies used to decrease emotional responses induced by the situation. Preference of one for a range of strategies is stable over time [59,60]. Context determines the choice of strategy and its efficiency. Coping is a concept broadly used in clinical health psychology to inquire about how one is dealing with one's disease [61].

Ahlström \& Sjöden [62] found that DM1 patients use emotion-related strategies twice as often as problem-focused ones. However, 97\% of their sample used "compensatory muscle movements or tricks" and 72\% used "an appliance or technical resources" (which are problem-focused strategies) in their everyday life. Predominant use of emotion-related coping strategies, such as feeling "Helpless/Hopeless" about the disease (83\%), "Social comparison" to other per- 
Table 3

Main results on personality

\begin{tabular}{ll}
\hline First author Year & Methodology (n) \\
\hline Bertrand JA [57] 2014 & Personality: NEO-FFI; \\
\cline { 2 - 2 } Self-esteem: RSES \\
Peric Sb [33] 2014 & PM1 (200) \\
& Psychopathology: MCMI-II \\
& Other: clinical interview \\
& DM1 (66)
\end{tabular}

Laberge L [56] 2013

Sistiaga A [45] 2010

Winblad S [51] 2006

Winblad S [50] 2005

Meola G [41] 2003

Delaporte C [40] 1998

\begin{tabular}{|c|c|}
\hline Fowler WM [48] 1997 & $\begin{array}{l}\text { Personality: CPI; } \\
\text { Psychopathology: MMPI } \\
\text { NMD (154 including } 42 \\
\text { DM1) }\end{array}$ \\
\hline Bungener C [8] 1996 & $\frac{\text { Personality: IPDE }}{\text { DM1 (15) }}$ \\
\hline
\end{tabular}

Palmer BW [22] $1994 \quad$ Personality: MCMI-II DM1 (21)

Fatigue: DSS; FSS;

Quality of life: SF-36;

LIFE-H

DM1 (200)

Personality: MCMI-II

DM1 (119), Healthy (54)

Main results

In general: scores within normal limits

27\%: higher N and lower A and Self-esteem

Differences between Mild $(n=48)$ and Adult onset $(n=152)$

At least one personality disorder: MCMI-II: $75.80 \%$; clinical interview: $58.10 \%$

$51.60 \%$ : dependent personality

$16.10 \%$ : paranoid personality

22.60\%: both dependent and paranoid

$32.20 \%$ : one or the other

Lower N: lower physical health function, psychological distress, and higher fatigue, severe muscular impairment

Lower mental health function: lower $\mathrm{C}, \mathrm{N}$ and daytime sleepiness

Narcissistic, antisocial, aggressive/sadistic, paranoid, psychotic thought, sincerity traits

Only aggressive/sadistic and paranoid traits are significantly higher in DM1 than controls

DM1: difficulties in recognizing expressions signaling negative emotion (anger, surprise, fear, and disgust)

Facial emotion recognition ability correlated with the sociability dimensions of the TCI (cooperativeness and dependence)

Signs of a personality disorder: DM1 : 20\%; Other muscle disorders: 5.60\%; Healthy: $3.40 \%$

None fulfilled DSM-IV criteria

Avoidant behavioral trait: DM1 higher than DM2 who scored higher than Healthy

Homogeneous personality profiles

Avoidant personality disorder: $26.70 \%(n=4)$

Obsessive-compulsive, passive-aggressive, and avoidant traits (anxious cluster)

Schizoid, schizotypal, and paranoid traits (odd cluster)

NMD: lower scores on sociability, sense of well-being, socialization, self-control, tolerance, good impression, achievement, intellectual efficiency, psychological mindedness, flexibility

Avoidant personality disorder: $26.70 \%(n=4)$

Obsessive-compulsive, passive-aggressive, avoidant, schizotypal, and paranoid traits (anxious and odd clusters)

Signs of dependency and submissiveness : $62 \%$

\begin{abstract}
Note: For more clarity, we did not develop all results. $C=$ Conscientiousness NEO-FFI scale; CPI = California Psychological Inventory; DM1 = Myotonic Dystrophy type 1; DM2 = Myotonic Dystrophy type 2; DSM III-R = Diagnostic and Statistical Manual of Mental Disorders III-Revised edition; DSS = Daytime Sleepiness Scale; EHD = Echelle d'Humeur Dépressive; FSHD = Facioscapulohumeral Dystrophy; FSS = Fatigue Severity Scale; HADS = Hospital Anxiety and Depression Scale; IPDE = International Personality Disorder Examination (// DSM III); LIFE-H = ; Assessment of Life Habits; MADRS = Montgomery and Asberg Depression Rating Scale; MCMI-II = Millon Clinical Multiaxial Inventory; MMPI = Minnesota Multiphasic Personality Inventory; N = Neuroticism NEO-FFI scale; NEO-FFI NEO-Five Factor Inventory; NMD = Neuromuscular diseases; RSES = Rosenberg Self-Esteem Scale; SCID-I\&II = Structured Clinical Interview for DSM Disorders I \& II (DSM-IV-TR); SCL-90 = Symptom Checklist-90-R; SDS = Zung Self-Rating Depression Scale; SF-36=36-item Short Form Health Survey; TCI = Temperament and Character Inventory.
\end{abstract}

sons with severe disease or healthier persons $(67 \%)$, "Anxious preoccupations" about the disease (55\%), and "Minimization" in terms of life expectations $(15 \%)$, was correlated with lower quality of life. All the problem-focused coping strategies following were also correlated to lower quality of life: "Accepts help or leaves it to others" (80\%), "Performs the task with aid of an applicant or other technical resource" (72\%), and "Establishment of control over everyday life" (13\%). Only two coping strategies, one of each 
kind, were correlated with a higher quality of life: "Stoic acceptation" of the disease (83\%; emotionfocused strategy) and "Tried alternative treatment" (60\%; problem-focused strategy). Nätterlund et al. [63] ran a study specifically on problem-focused coping. They found similar results as Ahlström \& Sjöden [62] about problem-focused coping not being used widely. Moreover, their results also showed that using "Devices and tricks" to cope with limitations related to the disease was the most problem-focused strategy used by DM1 patients. Nieto et al. [64] highlighted the influence of coping strategies on pain. In their study, the strategy "Asking for assistance" (which refers to problem-focused coping) was associated with an increase of the pain intensity and pain interference over time. The strategy "Resting" (which refers to emotion-focused coping) was associated with an increase of the pain intensity. Furthermore, the belief that emotions influence pain was associated with a decrease of psychological functioning over time. In their study, Miró et al. [65] found that pain-related catastrophizing (such as "Symptom magnification", "Rumination", and "Helplessness") was associated with poor psychological functioning and was increasing pain interference. On the contrary, perceived social support was associated with lower pain interference and better psychological functioning.

To summarize, DM1 patients use more emotionfocused coping strategies than problem-focused ones, even though most of the emotion-focused strategies are correlated with poor quality of life. The most common coping strategy used by DM1 patients is to have recourse to "devices and tricks" to confine the limitations inherent to their disease. Coping strategies relative to those limitations, to restricted life expectations, and to help from others have a negative impact on the patients' quality of life. However, perceived social support has a positive influence on pain interference. Disease acceptance and trying alternative treatment both have a positive impact on the patients' quality of life. Main results on coping are provided in Table 4.

\section{DISCUSSIONS}

This article reviewed articles published since 1979 on psychopathology features, personality, and coping in individuals with adult phenotypes of DM1. Moreover, we compared our findings with those exposed in the latest literature review [3]. Discussion will be articulated around the three issues that this review aimed to address: Are DM1 patients depressed? Do DM1 patients have a specific psychopathological, personality and coping profile? Are Ambrosini and Nurnberg's [3] findings confirmed? A fourth issue that has emerged from these results will be address: How can we conceptualize social difficulties in DM1?

Table 4

Main results on coping

\begin{tabular}{|c|c|c|}
\hline First author Year & Methodology (n) & Main results \\
\hline Nieto R [64] 2012 & $\begin{array}{l}\text { Pain: BPI; SOPA; } \\
\text { Coping: CSQ; CPCI } \\
\text { DM1 (37) }\end{array}$ & $\begin{array}{l}\text { High pain intensity associate with "asking for assistance" and } \\
\text { "resting", and high catastrophizing }\end{array}$ \\
\hline Miró J [65] 2009 & $\begin{array}{l}\text { Pain: NRS; BPI; SOPA; } \\
\text { Psychological functioning: SF-36; } \\
\text { Coping: CSQ; CPCI; } \\
\text { Social support: MSPSS } \\
\text { DM1 (78), FSHD (104) }\end{array}$ & $\begin{array}{l}\text { Pain-related catastrophizing associated with poor psychological } \\
\text { functioning and increasing pain interference } \\
\text { Perceived social support associated with lower pain interference and } \\
\text { better psychological functioning }\end{array}$ \\
\hline Nätterlund B [63] 1999 & $\begin{array}{l}\text { Coping: APC } \\
\text { DM1 (46) }\end{array}$ & $\begin{array}{l}\text { Problem-focused strategies are not often use } \\
\text { Most used coping strategy: "devices and tricks" }\end{array}$ \\
\hline Ahlström [62] 1996 & $\begin{array}{l}\text { Quality of life: SIP; KT; } \\
\text { Coping: MACS; } 2 \text { interviews ( } 3 \\
\text { months apart) about illness-related } \\
\text { problems and coping with these } \\
\text { problems } \\
\text { DM1 (32) }\end{array}$ & $\begin{array}{l}\text { Emotion-focused strategies use twice as often as problem-focused ones } \\
\text { Emotion-focused strategies are correlated with poorer quality of life }\end{array}$ \\
\hline
\end{tabular}

Note: For more clarity, we did not develop all results. APC = Assessment of Problem-focused Coping self-reported; BPI = Brief Pain Inventory; $\mathrm{CPCI}=$ Chronic Pain Coping Inventory; CSQ = Coping Strategies Questionnaire (Catastrophizing subscale only); DM1 = Myotonic Dystrophy type 1; KT = Kaasas test; MACS = Mental Adjustement to Cancer Scale; MSPSS = Multidimensional Scale of Perceived Social Support; NRS = Numerical Rating Scale pain intensity; SF-36 = 36-item Short Form Health Survey; SIP = Sickness Impact Profil; SOPA = Survey of Pain Attitudes; TCI = Temperament and Character Inventory. 


\section{ARE DM1 PATIENTS DEPRESSED?}

Results found in the literature concerning depression rates vary depending on the study [5-9, 11-22]. Yet, it initially appears that DM1 patients do show higher depression rates than both the general population and other somatic diseases [5, 7, 9, 23, 24, 29].

Brumback [29] and Brumback et al. [66] draw a hypothesis on the link to be made between DM1 and depression; they assumed that depression is a disease mechanism, associated with the patients' CNS deficit. Duveneck et al. [24] criticized this hypothesis: they found similar rates of depression in different muscular dystrophies and they concluded that depression is secondary to the disease. By comparing DM1 patients with and without white matter lesions, Winblad et al. [13] reached the conclusion that white matter lesions might "protect" DM1 patients against depression. Bungener, Jouvent and Delaporte [7] concluded that DM1 patients presented an emotional deficit rather than clinical depression.

On a different level, and while no personality profile has been determined, it can be hypothesized that the depression component in DM1 is partly linked to personality. Indeed, studies' results highlighted a tendency to negative emotionality and inhibition in DM1. This result was found in both the Five Factors Model, with elevated Neuroticism, and the Biosocial Personality Model, with high scores of Harm Avoidance [50, 57].

However, other authors criticized the methodology used to assess depression. Winblad et al. [13] performed an item-analysis on somatic items and cognitive affective items of the Beck Depression Inventory [67]. They found a significant difference between those two dimensions: DM1 patients tend to have high scores on somatic items and low scores on cognitive affective items. Somatic items include fatigue, sleepiness and somatic concerns, which are inherent to the disease. These results demonstrated the lack of sensibility of the BDI in the DM1 population. This criticism of the use of the BDI in DM1 population is also supported by Peric et al.'s [16] results. They suggested that the low depression rates found in their study, which they considered as closer to reality, are linked to the use of the HamD instead of the BDI.

Another hypothesis on the mechanisms underlying DM1 patients' emotional deficits had been made by Gallais et al. [5] where it might be due to symptoms of apathy, rather than depression. While no psychopathological pattern characteristic of DM1 can be concluded in the view of the current literature, apathy does appear as a typical symptom. Apathy was already reported in Ambrosini and Nurnberg's review [3]. Gallais et al. [5] and Rubinsztein et al. [6], thus, explored this symptom. They concluded that hypersomnolence and apathy were independent symptoms, even though resulting both from the genetic mutation. Indeed, hypersomnolence and apathy were not correlated with impairment or muscular weakness, meaning that there are not secondary to muscle disability. In addition, Gallais et al. [5] found that apathy was associated with the global cognitive status. Thus, apathy appears to be a specific symptom in DM1 that must be distinguished from depression, and may be associated with the CNS impairment involved in DM1.

Given these elements, it is difficult to conclude on depression rate among DM1 patients. Yet, it seems that DM1 patients do at least present an emotional deficit. Further studies taking into account these considerations have to been conducted to answer this issue.

\section{DO DM1 PATIENTS HAVE A SPECIFIC PSYCHOPATHOLOGICAL, PERSONALITY AND COPING PROFILE?}

It seems that DM1 patients did not experience more psychiatric disorders than the general population [36]. While DM1 patients did not fulfill criteria for psychiatric diagnosis, tendencies have been found in terms of personality and psychological functioning. Indeed, studies on psychopathology and personality report schizotypal, hypochondria, depression, paranoia, obsessive-compulsive, and passive-aggressive tendencies [5-9, 11-20, 23, 24, 29, 30, 33, 36-38, $40,45]$. In other terms, DM1 patients seem to present excessive preoccupation with body functions and orderliness, rigidity and relational difficulties. Studies with a dimensional approach of personality, confirmed this anxious and inhibited pattern [50]. Rigidity appearing in DM1 patients' personality could be linked to their cognitive impairment: in particular the lack of flexibility resulting from executive dysfunction. If there is an association between personality traits and cognitive deficits that are progressive, is the personality traits' profile of progressive nature as well? This question has to be further studied.

Bird et al. [30] concluded that DM1 patients have an excessive concern with body functions, depression, and inadequate social adjustment because 
they have to cope with a chronic disease. This pattern had already been seen in other medical conditions, such as multiple sclerosis or Duchenne muscular dystrophy, or such as type A and D personality, and Neuroticism in chronic disease [69-73]. So far, there is no psychopathological pattern characteristic of DM1 patients but the correlation between cognitive disorders and psychopathological problems could be a sign of a broader cerebral abnormality. Bird et al. [30] also concluded that patients with higher physical impairment tend to have higher psychopathological problems. Brumback et al. [29] compared DM1 patients with various neuromuscular diseases and a healthy control group. The fact that all patients with neuromuscular diseases, including DM1, showed hypochondria and hysteria manifestations leads authors to hypothesize that these manifestations could be typical of somatic diseases. In view of the current literature it can therefore be concluded that DM1 patients show psychological distress, such as anxiety and preoccupations with body functions, rigidity and important interpersonal difficulties, but no more psychiatric disorders than the general population. Several hypotheses on the link between DM1 and psychological distress may be envisaged: the chronicity of the disease, the somatic aspect, or a cerebral abnormality.

Regarding coping, DM1 patients showed a strong preference for emotion-focused strategies even though the most used strategy was using "compensatory muscle movements or tricks" (which is a problem-focused strategy) [62, 63]. DM1 patients' rigidity, previously described, is also reflected in the choice of coping strategies: DM1 patients seem to keep widely using emotion-focused coping strategies even if they are associated with a lower quality of life. Ahlström and Sjöden [62] hypothesized that this tendency results from their lack of control on the consequences of the disease.

\section{ARE AMBROSINI AND NURNBERG'S [3] FINDINGS CONFIRMED?}

Our review only partially confirms Ambrosini and Nurnberg's [3]: DM1 patients do show schizoid and paranoid traits [8, 30, 33, 38, 40, 45]. However, we did not find any study reporting hypomanic manifestations. In addition to the fact that the terms "epileptoid" and "hysteroid" are not used anymore in recent studies; we did not find any study describing atypical fits and sudden paralysis or hallucinations and delusional thoughts. Finally, prevalence of schizophrenia, previously found in Ambrosini and Nurnberg's review [3], is not reported in the recent literature. Rather than a diagnosis of schizophrenia, it seems that DM1 patients showed schizoid and schizotypal traits $[8,30,40]$.

\section{HOW CAN WE CONCEPTUALIZE SOCIAL DIFFICULTIES IN DM1?}

This review highlights some elements which could partly explain the social difficulties found in a proportion of DM1 patients: schizotypal, paranoia, obsessive-compulsive (interpersonal control) and passive-aggressive tendencies are a first element explaining this problem. Sistiaga et al. [45] ask themselves if these attitudes are specific patterns of personality or simply the consequence of DM1 patients' motor and cognitive impairment. Personality disorders were not predominant in DM1 patients, but when one was diagnosed, the most common was the avoidant personality disorder [8, 39]. One of the symptoms of this personality disorder is specifically social inhibition. The rest of this personality disorder's definition ("feelings of inadequacy, and hypersensitivity to negative evaluation" [39]) follows the same line. Regarding personality traits, even though no specific profile has been highlighted, some patients showed high scores on Neuroticism and low scores on Agreeableness [57]. Two components of Neuroticism can be especially linked to social withdrawal: malaise in the presence of others and shyness. Agreeableness refers to the qualitative aspect of interpersonal interaction, which includes altruism, trust in others, compliance, and sensibility to others. Furthermore, authors studying DM1 patients' ability to recognize facial expressions made the link between the fact that DM1 patients show lower sensitivity to anger and disgust and white matter lesions conduction to limbic system dysfunctions. This system is underlying social cognitive impairment, which might partly explain DM1 patients' difficulties to take part in social situations $[52,53]$. In addition to these difficulties in emotion recognition, DM1 patients also show a reduced facial expressivity (due to facial muscle weakness) which could participate to their social difficulties. DM1 patients' social withdrawal might also be reinforced by their choice of coping strategies. The ones involving others help are associated with 
a poor quality of life [62]. Evolution of the disease and the increased impairments going with it can be difficult to accept for patients. Regarding the part of depression and anxiety, according to Bungener et al.'s [8] conclusion, it cannot explain neuropsychiatric DM1 characteristics, such as social withdrawal and isolation.

Grahams et al. [74] pointed out the potential of Acceptance and Commitment Therapy (ACT; a form of Cognitive Behavioral Therapy) and traditional Cognitive Behavioral Therapy (CBT) in muscle disorders to improve quality of life and mood even though patients experience increasing muscle weakness and impairments. ACT had been found efficient to reduce distress in patients with multiple sclerosis [75]. In Europe, a study on the efficiency of traditional CBT for managing DM1-related symptoms (such as fatigue and reduced activity) is currently being conducted [76]. In a more recent paper, Grahams et al. [77] discuss the results of Fujino et al. [78] and point out the potential therapeutic benefits of cognitive rehabilitation for myotonic dystrophy patients. Authors stressed that even the evaluation itself (prior to cognitive rehabilitation interventions) could be beneficial for the patients' and their relatives and clinicians' perception of the patients' difficulties. We believe that the Cognitive Remediation Therapy could also be a lead to explore for the treatment of DM1 patients' social cognitive impairment. This method has already been found effective to significantly improve several cognitive domains including social cognition in schizophrenia [79]. However, the impact of apathy as a potential limitation for DM1 patients' participation in classically structured psychotherapies has not been demonstrated yet, but may have to be considered.

\section{LIMITATIONS}

Our exclusion criteria are themselves a limitation; we did not include articles written in languages other than English or French, and therefore we did not take into account a part of the available literature. The choice to not include qualitative studies also deprived our review of another perspective of DM1 patients' difficulties.

The sample size of most of the studies included in this review is also a limitation. Only two articles had a sample of 200 participants, two articles had a sample between 100 and 200 participants, and eight articles included between 50 and 100 participants. At the end, the majority of the studies we reviewed (27 studies) included less than 50 participants. But on the other hand, the fact that DM1 is a rare disease makes it difficult to constitute larger samples.

The superposition of psychiatric and somatic symptoms adds another difficulty for making proper conclusions. Apathy, hypersomnolence and depression present clinically overlapping symptoms such as fatigue, lack of motivation, diminished activity levels, and social withdrawal. These symptoms can be seen as depressive symptoms or DM1-related symptoms depending on the tool used.

Finally, the lack of homogeneity of the scales used among studies constituted a problem to compare the different studies, and we were not able to conduct a proper meta-analysis. Issues of the methodology used to assess depression in studies we reviewed have already been addressed. Regarding personality rates in DM1 patients, Delaporte [40] suggests that this issue is due to the differences between personality tests used in studies.

\section{CONCLUSIONS}

In conclusion, this review permitted the clarification of the psychological functioning of DM1 patients. Results on psychopathology highlighted some tendencies: interpersonal difficulties, apathy, dysphoria, and concerns about bodily functioning $[5,6,8,21,29,30,33,37,38,40,41,45,48$, $50,51,57]$. Yet, those psychopathological manifestations seem to be variable, with the exception of apathy which is a recurrent symptom in DM1. Moreover, apart from depression and personality disorders, DM1 patients do not show more psychiatric disorders than the general healthy population [36]. Depression results should be considered while keeping in mind theoretical and methodological issues regarding its evaluation. Furthermore, future research must use instruments validated in the DM1 population to assess depression. Several symptoms of personality disorders were found in the DM1 population, such as obsessive-compulsive, schizotypal, paranoid, and passive-aggressive traits $[8,33,38,40,45]$. The most recurrent personality disorder found in this population is the avoidant personality disorder $[8,40]$. Based on tendencies observed among DM1 patients, we did provide elements to conceptualize their social withdraw. Apathy, social inhibition relative to personality 
traits, difficulties to interpret others' emotions, and the malaise felt by the patients when others have to help them get things done could partially explain DM1 patients' difficulty to interact with others.

\section{CONFLICTS OF INTEREST}

\section{Authors have no conflict of interest to report.}

\section{REFERENCES}

[1] Norwood FL, Harling C, Chinnery PF, Eagle M, Bushby K, Straub V. Prevalence of genetic muscle disease in Northern England: In-depth analysis of a muscle clinic population. Brain. 2009;132:3175-86.

[2] Gagnon C, Noreau L, Moxley RT, et al. Towards an integrative approach to the management of myotonic dystrophy type 1. J Neurol Neurosurg Psychiatry. 2007;78:800-6.

[3] Ambrosini PJ, Nurnberg HG. Psychopathology: A primary feature of myotonic dystrophy. Psychosomatics. 1979;20(6):393-9.

[4] Maas O, Paterson AS. Mental changes in families affected by dystrophia myotonica. Lancet. 1937;1:21-3.

[5] Gallais B, Montreuil M, Gargiulo M, Eymard B, Gagnon C, Laberge L. Prevalence and correlates of apathy in myotonic dystrophy type 1. BMC Neurol. 2015;15:148-56.

[6] Rubinsztein JS, Rubinsztein DC, Goodburn S, Holland AJ. Apathy and hypersomnia are common features of myotonic dystrophy. J Neurol Neurosurg Psychiatry. 1998;64:510-5.

[7] Bungener C, Jouvent R, Delaporte C. Psychopathological and emotional deficits in myotonic dystrophy. J Neurol Neurosurg Psychiatry. 1998;65:353-6.

[8] Bungener C, Picq C, Lauriot-Prevost MC, Delaporte C. Fonction cognitives, affects et personnalité chez des patients atteints de dystrophie myotonique. Perspectives Psy. 1996;35(4):21-6.

[9] Colombo G, Perini GI, Miotti MY, Armani M, Angelini C. Cognitive and psychiatric evaluation of 40 patients with myotonic dystrophy. Ital J Neurol Sci. 1992;13:53-8.

[10] Kessler RC, Bromet EJ. The epidemiology of depression across cultures. Annu Rev Public Health. 2013;34: 119-38.

[11] Rakocevic-Stojanovic V, Peric S, Madzarevic R, et al. Significant impact of behavioral and cognitive impairment on quality of life in patients with myotonic dystrophy type 1 . Clin Neurol Neurosurg. 2014;126:76-81.

[12] Minnerop M, Weber B, Schoene-Bake JC, et al. The brain in myotonic dystrophy 1 and 2: Evidence for a predominant white matter disease. Brain. 2011;134:3527-43.

[13] Winblad S, Jensen C, Månsson JE, Samuelsson L, Lindberg C. Depression in Myotonic Dystrophy type 1: Clinical and neuronal correlates. Behav Brain Funct. 2010;6:25-32.

[14] Timman R, Tibben A, Wintzen AR. Myotonic Dystrophy: The burden for patients and their partners. J Rehabil Med. 2010;42:823-30.

[15] Antonini G, Soscia F, Giubilei F, et al. Health-related quality of life in myotonic dystrophy type 1 and its relationship with cognitive and emotional functioning. J Rehabil Med. 2006;38:181-5.

[16] Peric S, Pavlovic A, Ralic V, et al. Transcranial sonography in patients with myotonic dystrophy type 1 . Muscle Nerve. 2014(a);50:278-82.
[17] Peric S, Rakocevic-Stojanovic V, Stevic Z, et al. Healthrelated quality of life in patients with myotonic dystrophy type 1 and amyotrophic lateral sclerosis. Acta Neurol Belg. 2010;110:71-7.

[18] Boyer FC, Rapin A, Calmus A, et al. HADS scale in adults suffering from Steinert myotonia: Reproducibility and internal consistency. Ann Phy Rehabil Med. 2011;54(1):238.

[19] Pais-Ribeiro J, Silva I, Ferreira T, Martins A, Meneses R, Baltar M. Validation study of a Portuguese version of the Hospital Anxiety and Depression Scale. Psychol Health Med. 2007;12(2):225-35.

[20] Cuthill J, Gattereau A, Viguié F. Myotonic Dystrophy of Steinert: Are Anxiety and Depression Necessarily Concomittants? Can J Psychiatry. 1988;33:203-6.

[21] Kierkegaard M, Harms-Ringdahl K, Holmqvist LW, Tollbäck A. Functioning and disability in adults with myotonic dystrophy type 1. Disabil Rehabil. 2011;33:182636.

[22] Palmer BW, Brauer BK, Chang L, Lee A, Black S. Cognitive deficits and personality patterns in maternally versus paternally inherited myotonic dystrophy. J Clin Exp Neuropsychol. 1994;16(5):784-95.

[23] Kobayakawa M, Tsuruya N, Kawamura M. Theory of mind impairment in adult-onset myotonic dystrophy type 1 . Neurosci Res. 2012;72:341-6.

[24] Duveneck MJ, Portwood MM, Wicks JJ, Lieberman JS. Depression in Myotonic Muscular Dystrophy. Arch Phys Med Rehabil. 1986;67(12):875-7.

[25] Phillips MF, Steer HM, Soldan JR, Wiles CM, Harper PS. Daytime somnolence in myotonic dystrophy. J Neurol. 1999;246:275-82.

[26] Rose MR, Sadjadi R, Weinman J, Akhtar T, Pandya S, Kissel JT, Jackson CE, Muscle Study Group. Role of Disease Severity, Illness Perceptions, and Mood on Quality of Life in Muscle Disease. Muscle Nerv. 2012;46: 351-59.

[27] Hathaway SR, Mckinley JC. A Multiphasic Personality Schedule (Minnesota): I. Construction of the Schedule. J Psychol. 1940;10:249-54.

[28] Butcher JN, Perry J. Personality assessment in treatment planning. New York: Oxford University Press; 2008.

[29] Brumback RA. Disturbed personality and psychosocial adjustment in myotonic dystrophy: Relationship to intellectual/cognitive function and underlying affective disorder (depression). Psychol Rep. 1987;60:783-96.

[30] Bird TD, Follett C, Griep E. Cognitive and personality function in myotonic muscular dystrophy. J Neurol Neurosurg Psychiatry. 1983;46:971-80.

[31] American Psychiatric Association. Diagnostic and Statistical manual of Mental disorders (3rd ed.). American Psychiatric Publishing. 1980.

[32] Craig RJ. Psychological assessment with the Millon Clinical Multiaxial Inventory (II): An interpretive guide. Odessa, F: Psychological Assessment Resources. 1993.

[33] Peric S, Sreckov M, Basta I, Lavrnic D, Vujnic M, Marjanovic I, Rakocevic Stojanovis V. Dependent and paranoid personality patterns in myotonic dystrophy type A. 2014(b);129:219-25.

[34] Peric S, Rakocevic Stojanovic V, Basta I, et al. Influence of multisystemic affection on health-related quality of life in patients with myotonic dystrophy type 1. Clin Neurol Neurosurg. 2013;115:270-75.

[35] Graham CD, Rose MR, Grunfeld EA, Kyle SD, Weinman J. A Systematic Review of Quality of Life in Adults with Muscle Disease. J Neurol. 2011;258:1581-92. 
[36] Kalkman JS, Schillings ML, Zwarts MJ, Van Engelen BGM, Bleijenberg G. Psychiatric disorders appear equally in patients with myotonic dystrophy, facioscapulohumeral dystrophy, and hereditary motor and sensory neuropathy type I. Acta Neurol Scand. 2007;115:265-70.

[37] Franzese A, Antonini G, Iannelli M, et al. Intellectual functions and personality in subjects with noncongenital myotonic muscular dystrophy. Psychol Rep. 1991;68: 723-32.

[38] Serra L, Silvestri G, Petrucci A, et al. Abnormal Functional Brain Connectivity and Personality Traits in Myotonic Dystrophy Type 1. JAMA Neurol. 2014;71(5):603-11.

[39] American Psychiatric Association. Diagnostic and statistical manual of mental disorders (5th ed.). Arlington, VA: American Psychiatric Publishing. 2013

[40] Delaporte C. Personality Patterns in Patients with Myotonic Dystrophy. Arch Neurol. 1998;55:635-40.

[41] Meola G, Sansone V, Perani D, Scarone S, Cappa S, Dragoni C. Executive dysfonction and avoidant personality trait in myotonic dystrophy type 1 (DM-1) and in proximal myotonic myopathy (PROMM/DM-2). Neuromuscul Disord. 2003;13(10):813-21.

[42] First MB, Gibbon M, Spitzer RL, Williams JBW, Benjamin LS. Structured Clinical Interview for DSM-IV Axis II Personality Disorders, (SCID-II). Washington, DC: American Psychiatric Press, Inc. 1997.

[43] First MB, Spitzer RL, Gibbon M, Williams JBW. Structured Clinical Interview for DSM- IV-TR Axis I Disorders, Research Version, Non-patient Edition. (SCID-I/NP). New York: Biometrics Research, New York State Psychiatric Institute. 2002.

[44] American Psychiatric Association. Diagnostic and statistical manual of mental disorders (4rd ed., revised). Washington, DC: American Psychiatric Publishing, 2000.

[45] Sistiaga A, Urreta I, Jodar M, et al. Cognitive/personality pattern and triplet expansion size in adult myotonic dystrophy type 1 (DM1): CTG repeats, cognition and personality in DM1. Psychol Med. 2010;40:487-95.

[46] Huang Y, Kotov R, De Girolamo G, et al. DSM-IV personality disorders in the WHO World Mental Health Surveys. Br J Psychiatry. 2009;195:46-53.

[47] Gough HG. California Psychological Inventory Administrator's Guide. Palo Alto, CA: Consulting Psychologists Press, Inc. 1987.

[48] Fowler WM, Abresch RT, Koch TR, Brewer ML, Bowden RK, Wanlass RL. Employment profiles in neuromuscular diseases. Am J Phys Med Rehabil. 1997;76:26-37.

[49] Cloninger RC, Svrakic DM, Przybeck TR. A Psychobiological Model of Temperament and Character. Arch Gen Psychiatry. 1993;50(12):975-90.

[50] Winblad S, Lindberg C, Hansen S. Temperament and character in patients with classical myotonic dystrophy type 1 (DM-1). Neuromuscul Disord. 2005;15(4): 287-92.

[51] Winblad S, Hellström P, Lindberg C, Hansen S. Facial emotion recognition in myotonic dystrophy type 1 correlates with CTG repeat expansion. J Neurol Neurosurg Psychiatry. 2006;77:219-23.

[52] Kobayakawa M, Tsuruya N, Takeda A, Suzuki A, Kawamura M. Facial emotion recognition and cerebral white matter lesions in myotonic dystrophy type 1. J Neurol Sci. 2010;290:48-51.

[53] Takeda A, Kobayakawa M, Suzuki A, Tsuruya N, Kawamura M. Lowered sensitivity to facial emotions in myotonic dystrophy type 1. J Neurol Sci. 2009;280:35-9.
[54] John OP, Naumann LP, Soto CJ. Paradigm Shift to the Integrative Big Five Trait Taxonomy: History, Measurement, and Conceptual Issues. In: John OP, Robins RW, Pervin LA, editors. Handbook of Personality: Theory and Research. 3rd ed., New York: Guilfort. 2008.

[55] Costa PT, Mc Crae RR. Four ways Five Factors are Basic. Pers Indiv Dif. 1992;13:653-66.

[56] Laberge L, Mathieu J, Auclair J, Gagnon E, Noreau L, Gagnon C. Clinical, Psychosocial, and Central Correlates of Quality of Life in Myotonic Dystrophy Type 1 Patients. Eur Neurol. 2013;70:308-15.

[57] Bertrand JA, Jean S, Laberge L, et al. Psychological characteristics of patients with myotonic dystrophy type 1 . Acta Neurol Scand. 2014;132(1):49-58.

[58] Lazarus RS, Folkman S. Stress, Appraisal, and Coping. New York: Springer. 1984.

[59] Vollrath M, Torgersen T, Alnaes R. Personality as long-term predictor of coping. Pers Ind Dif. 1995;18(1):117-25.

[60] Costa P, Somerfield M, Mc Crae R. Personality and coping: A reconceptualization. In Handbook of coping: Theory, research and applications New York:Wiley. 1996; 44-61.

[61] Koleck M, Bruchon-Schweitzer M, Bourgeois ML. Stress et coping: Un modèle intégratif en psychologie de la santé. Ann Med Psychol. 2003;161(10):809-15.

[62] Ahlström G, Sjöden P. Coping with illness-related problems and quality of life in adult individuals with muscular dystrophy. J Psychosom Res. 1996;41(4):365-76.

[63] Nätterlund B, Ahlström G. Problem-focused Coping and Satisfaction with Activities of Daily Living in Individuals with Muscular Dystrophy and Postpolio Syndrome. Scand J Caring Sci. 1999;13:26-32.

[64] Nieto R, Raichle KA, Jensen MP, Miró J. Changes in pain-related beliefs, coping, and catastrophizing predict changes in pain intensity, pain interference, and psychological functioning in individuals with Myotonic Muscular Dystrophy and Facioscapulohumeral Dystrophy. Clin J Pain. 2012;28(1):47-54.

[65] Miró J, Raichle KA, Carter GT, et al. Impact of biopsychosocial factors on chronic pain in persons with myotonic and fascioscapulohumeral muscular dystrophy. Am J Hosp Palliat Med. 2009;26(4):308-19.

[66] Brumback RA, Carlson KM, Wilson H, Staton RD. Myotonic dystrophy as disease of abnormal membrane receptors: Hypothesis of pathophysiology and new approach to treatment. Med Hypotheses. 1981;7: 1059-66.

[67] Beck AT, Steer RA, Brown GK. BDI-II: Beck Depression Inventory Manual (2nd ed.). San Antonio, TX: Psychological Corporation, 1996.

[68] Hamilton M. A rating scale for depression. J Neurol Neurosurg Psychiatry. 1960;23:56-62.

[69] Leibowitz D, Dubowitz V. Intellect and behavior in Duchenne muscular dystrophy. Dev Med Child Neurol. 1981;23:557-90.

[70] Lynch HT, Tips RL, Krush A. Psychodynamics in a chronic debilitating hereditary disease (myotonia dystrophica). Arch Gen Psychiatry. 1966;14:153-7.

[71] Lohse T, Rohrmann S, Richard A, Bopp M, Faeh D. Type A personality and mortality: Competitiveness but not speed is associated with increased risk. Atheroscler. 2017;262:1924; doi: 10.1016/j.atherosclerosis.2017.04.016

[72] Schoormans D, Husson O, Denollet J, Molsis F. Type D personality a risk factor for all- cause mortality? A prospective population-based study among 2625 colorectal cancer 
survivors from the PROFILES registry. J Psychosom Res. 2017;96:76-83; doi: 10.1016/j.jpsychores.2017.03.004

[73] Hyphantis T, Goulia P, Carvalho AF. Personality traits, defense mechanisms and hostility features associated with somatic symptom severity in both health and disease. J Psychosom Res. 2013;75:362-9.

[74] Graham CD, Simmons Z, Stuart SR, Rose MR. The Potential of Psychological Interventions to Improve Quality of Life and Mood in Muscular Disorders. Muscle Nerve. 2015;52:131-6; doi: 10.1002/mus.24487

[75] Moss-Morris R, Dennison L, Landau S, Yardley L, Silber E, Chalder T. A randomized controlled trial of cognitive behavioral therapy (CBT) for adjusting to multiple sclerosis (the saMS trial): Does CBT work and for whom does it work? J Consult Clin Psychol. 2013;81:251-62.

[76] Van Engelen B, and The OPTIMISTIC Consortium. Cognitive behaviour therapy plus aerobic exercise training to increase activity in patients with myotonic dystrophy type 1 (DM1) compared to usual care (OPTIMISTIC): Study protocol for randomised controlled trial. Trials. 2015;16:224-43.

[77] Graham CD, Kemp S, Radakovic R, Kapur N. Clinical neuropsychology in the management of myotonic dystrophy. Muscle Nerve. 2018;57:701-4.

[78] Fujino H, Shingaki H, Suwazono S, Ueda Y, Wada C, Nakayama T, et al. Cognitive impairment and quality of life in patients with myotonic dystrophy type 1 . Muscle Nerve. 2018;XX:XXX-XXX.

[79] Wykes T, Huddy V, Cellard C, Mcgurk Sr, Czobor P. A meta-analysis of cognitive remediation for schizophrenia: Methodology and effect sizes. Am J Psychiatry. 2011;168(5):472-85. 